\title{
Equivalência de Estímulos entre Três Formas de Apresentação de Problemas Aritméticos: Um Estudo com Adultos e Idosos
}

\author{
Verônica Bender Haydu ${ }^{\mathbf{1}}$ \\ Departamento de Psicologia Geral e Análise do Comportamento da Universidade Estadual \\ de Londrina, Londrina, PR, Brasil \\ Carolina Marroni Lorencete \\ Centro de Apoio Multidisciplinar em Educação Especial da Prefeitura Municipal \\ de Capivari, Capivari, SP, Brasil \\ Simone Deperon Eccheli \\ Universidade Tecnológica Federal do Paraná, Londrina, PR, Brasil
}

\begin{abstract}
Resumo
Analistas do comportamento têm feito importantes contribuições para a educação, aumentando recentemente as contribuições para o ensino de comportamentos matemáticos. O presente estudo visou investigar se a formação de relações de equivalência entre diferentes formas de apresentação de problemas aritméticos melhora o desempenho na resolução de problemas. Participaram quatro mulheres, em fase de alfabetização, com idades entre 37 e 71 anos. Inicialmente foi aplicado um pré-teste composto de 45 problemas aritméticos apresentados de diferentes formas (operação, sentença-problema e balança). As sessões de ensino foram realizadas para estabelecer relações condicionais entre balança e operação (AB) e balança e sentença-problema (AC), envolvendo nove conjuntos de estímulos de cada tipo de apresentação dos problemas aritméticos para formar nove classes de estímulos equivalentes. O procedimento de ensino foi repetido até que no mínimo $90 \%$ de respostas corretas fossem emitidas. A formação das classes de estímulos equivalentes foi testada por meio dos testes de linha de base ( $\mathrm{AB}$ e $\mathrm{AC}$ ), simetria (BA e CA) e equivalência (BC e CB). Por último, foi aplicado o pós-teste, com os mesmos problemas do pré-teste, mas em diferente ordem. Todas as participantes apresentaram aumento na porcentagem de acertos no pós-teste, comparado com o pré-teste. Concluiu-se que o estabelecimento de relações de equivalência entre as diferentes formas de apresentação de problemas aritméticos contribuiu para melhorar o desempenho de adultos e idosos na resolução de problemas com incógnitas em diferentes posições.
\end{abstract}

Palavras-chave: Classes de estímulos equivalentes, resolução de problemas aritméticos, análise do comportamento, adultos e idosos.

\section{Stimulus Equivalence among Three Forms of Presentation of Arithmetic Problems: A Study with Adults and Elderly}

\begin{abstract}
Behavior analysts have made important contributions to education, recently increasing contributions to teaching mathematical behaviors. This study aimed to investigate if the formation of equivalence relations among different forms of presentation of arithmetic problems improves problem solving perfor-
\end{abstract}

Endereço para correspondência: Rua Duque de Caxias, 1235, Rolândia, PR, Brasil 86605-180. E-mail: haydu@uel.br 
mances. Participated four women in the literacy phase, aged between 37 and 71 years. Initially a pretest was applied composed of 45 arithmetic problems presented in different forms (operation, word-problem and balance). Teaching sessions were conducted to establish conditional relations between balance and operation (A-B), and balance and word problem (A-C), involving nine sets of stimuli of each type of presentation of the arithmetic problems to form nine stimuli equivalent classes. The sessions and the teaching procedure were repeated until at least $90 \%$ correct responses were emitted. The formation of equivalent classes was tested by means of baseline tests (A-B, B-C), symmetry (B-A, C-A) and equivalence (B-C, C-B). Finally, a post-test with the same problems of the pretest, but in different order, was applied. All participants showed increases in the percentage of correct responses in the posttest compared with the pretest. It was concluded that the establishment of equivalence relations between different forms of the presentation of arithmetic problems contributed to improve the performance of adults and seniors in solving problems with the unknowns set in different position.

Keywords: Classes of equivalent stimuli, arithmetic problem solving, behavior analysis, adults and seniors.

\section{La Equivalencia de Estímulos entre Tres Formas de Presentación de Problemas Aritméticos: Un Estudio con Adultos y Ancianos}

\section{Resumen}

Los analistas de la conducta han hecho importantes contribuciones a la educación, incrementando recientemente contribuciones a la enseñanza de comportamientos matemáticos. El presente estudio tuvo como objetivo investigar si la formación de relaciones de equivalencia entre diferentes formas de la presentación de problemas aritméticos mejora el rendimiento en la resolución de problemas. Participaran cuatro mujeres en la fase de alfabetización, con edades entre 37 y 71 años. Un pre-test comprendiendo 45 problemas aritméticos en diferentes formas (operación, sentencia-problema y balanza) se aplicó. Las sesiones de enseñanza establecerán relaciones condicionales entre la balanza y la operación ( $\mathrm{AB})$ y entre balanza y sentencia-problema (AC), comprendiendo nueve conjuntos de estímulos de cada tipo de presentación de problemas aritméticos para formar nueve clases de equivalencia. El procedimiento de enseñanza se repitió hasta que al menos $90 \%$ de respuestas correctas se emitieron. La formación de clases equivalentes fue probado en pruebas de línea de base ( $\mathrm{AB}$ y AC), simetría (BA y CA) y equivalencia (BC y CB), con los mismos problemas del pre-test, pero en diferente orden. Por último, se aplicó el post-test, con los mismos problemas en la prueba previa, pero en diferente orden. Todos los participantes mostraron un aumento en el porcentaje de respuestas correctas en el post-test en comparación con el pre-test. Se concluyó que el establecimiento de relaciones de equivalencia entre diferentes formas de presentación de problemas de aritmética contribuyó para mejorar el rendimiento de los adultos y de los ancianos en la solución de problemas con incógnitas en diferentes posiciones.

Palabras clave: Clases de estímulos equivalentes, resolución de problemas aritméticos, análisis de comportamiento, adultos y ancianos.

As contribuições que os analistas do comportamento têm feito para a Educação podem ser consideradas importantes e significativas, conforme já foi sugerido 42 anos atrás por Bijou (1970). Essas contribuições são claras porque os conceitos e princípios da análise do comportamento são aplicáveis de forma direta a contextos de ensino, o que é viabilizado por meio de arranjo de contingências de reforço, de programação de técnicas instrucionais, no desenvolvimento de materiais didáticos, no estabelecimento de variáveis motivacionais etc.

Uma revisão bibliográfica feita por Haydu (2012) das contribuições para a Educação permi- 
tiu constatar que essa é uma das áreas "que tem o maior número de publicações feitas por analistas do comportamento" (p. 24), sendo as pesquisas empíricas de análise aplicada do comportamento privilegiadas por periódicos como o Journal of Applied Behavior Analysis e o Journal of Behavioral Education. Além disso, são encontrados, na bibliografia, livros e capítulos de livros que descrevem um conjunto de princípios que permitem arranjar as contingências de ensino para a aprendizagem (e.g., Matos, 1992; Skinner, 1968), estudos que focalizaram a produção de Skinner para a Educação e para a formação de professores (e.g., Luna, 2007; Zanotto, 2000) e coletâneas em que pesquisas empíricas e teórico/conceituais foram organizadas (e.g., Heward et al., 2004; Hübner \& Marinotti, 2004; Marmo, 2002).

Dentre as contribuições dos analistas do comportamento brasileiros para Educação, vem aumentando a publicação de pesquisas que investigaram o ensino e a aprendizagem de comportamentos matemáticos. Essa bibliografia inclui estudos sobre o conceito de número e ordenação (Monteiro \& Medeiros, 2002; Resende, Elias, \& Goyos, 2012; ver revisão em Lorena, Castro-Caneguim, \& Carmo, 2013), resolução de problemas (Haydu, Costa, \& Pullin, 2006; Henklain \& Carmo, 2013a, 2013b), manejo de dinheiro (Magalhães, Assis, \& Rossit, 2012; Rossit \& Goyos, 2009) etc., sendo o modelo da equivalência de estímulos o mais aplicado nos estudos mais recentes (Del Rey, 2009). O destaque desse tema - equivalência de estímulos - nas pesquisas de análise do comportamento é decorrente em parte do fato de esse modelo ser relevante para a análise de comportamento simbólico (de Rose \& Bortoloti, 2007).

No contexto do ensino da Matemática, o desempenho de comportamentos simbólicos pode ser identificado na aprendizagem do conceito de número (Drachenberg, 1973), do manuseio de dinheiro (Magalhães et al., 2012; Rossit \& Goyos, 2009), da aquisição de comportamento algébrico (Dalto, 2012; Mayfield \& Chase, 2002), o ensino da técnica de inferência estatística (Fienup, Covey, \& Critchfield, 2010) e da resolução de problemas (Haydu et al., 2006;
Henklain \& Carmo, 2013a, 2013b), dentre outros. A emissão desses comportamentos implica em um repertório comportamental que inclui discriminações condicionais e formação de classes de equivalência. No caso da resolução eficaz de problemas, não só esses comportamentos são requeridos, mas também a elaboração de regras relacionais eficientes, originadas pelo contato direto com as contingências envolvidas em situações semelhantes no passado (Skinner, 1968), sendo que a forma de apresentação dos problemas e a posição da incógnita se constituem dificuldades para a aprendizagem (Carpenter \& Moser, 1983; Hiebert, 1982). Em suma, para resolver problemas, o aprendiz deve aprender uma linguagem específica, com sintaxe e símbolos próprios e emitir comportamentos precorrentes que possibilitem a resolução do problema.

Os comportamentos precorrentes são formas de manipulação das variáveis ambientais, que podem ser públicas ou privadas, as quais estabelecem as condições para a emissão da resposta solução que, por sua vez, produz reforços contingentes (Skinner, 1984). Nos casos em que esses comportamentos não foram previamente adquiridos, muitas vezes, devem ser explicitamente ensinados. Para investigar como esse ensino pode ser feito, foram desenvolvidos estudos analítico-comportamentais, em que comportamentos precorrentes públicos foram ensinados para a resolução de problemas aritméticos em forma de sentenças linguísticas (word ploblems - designados aqui "sentenças-problema").

O ensino de comportamentos precorrentes a participantes com desenvolvimento atípico para resolverem problemas de adição e de subtração foi realizado no estudo desenvolvido por Neef, Nelles, Iwata e Page (2003). A incógnita nos problemas era apresentada nas três possíveis posições. Por exemplo, "Se Maria tinha A objetos e ficou com C, quantos ela ganhou?". Esse problema corresponde à operação $\mathrm{a}+\mathrm{x}=\mathrm{c}$, sendo " $\mathrm{x}$ " a incógnita. Os demais problemas do estudo eram correspondentes às seguintes operações: $\mathrm{x}+\mathrm{b}=\mathrm{c}, \mathrm{a}+\mathrm{b}=\mathrm{x}, \mathrm{x}-\mathrm{b}=\mathrm{c}, \mathrm{a}-\mathrm{x}=\mathrm{c}, \mathrm{a}-\mathrm{b}=\mathrm{x}$. Os comportamentos precorrentes consistiam em especificar em sequência, abaixo das sentenças-problema delimitados por círculos para os números e um 
quadrado para o sinal de adição ou subtração, o seguinte: (a) a palavra que indicava o número de objetos que o sujeito da ação possuía no início; (b) o verbo que determinava que objetos eram adicionados ou subtraídos, o que especificava a alteração a ser realizada; (c) esse verbo também indicava a operação a ser executada; (d) a frase que denotava o número final dos objetos que o sujeito da ação possuiria que era o valor resultante; (e) a questão do problema que caracteriza qual afirmação é a solução. Essas respostas eram seguidas de consequências reforçadoras e de correções na fase de ensino, a qual foi precedida e seguida por testes para o estabelecimento da linha de base e a generalização de estímulos. Nas fases de teste e de ensino, os participantes eram instruídos a ler as sentenças-problema e emitir o comportamento precorrente correspondente aos cinco itens especificados na sequência de prompts verbais a ele apresentados. Caso o participante não emitisse a resposta ou errasse, a resposta correta era fornecida a ele. Os resultados do estudo permitiram constatar que a intervenção foi eficaz para desenvolver os comportamentos precorrentes que passaram a ocorrer diante de problemas que não haviam sido previamente ensinados (generalização de estímulos) e que o número de problemas corretamente resolvidos aumentou.

Uma replicação do estudo de Neef et al. (2003) foi realizada por Levingston, Neef e Cihon (2009), no qual foram ensinados comportamentos precorrentes para a resolução de problemas aritméticos em forma de sentenças-problema de multiplicação e de divisão. O procedimento de ensino consistiu em apresentar instruções sequenciais para que os participantes identificassem e escrevessem: (a) o nome dos objetos da sentença-problema; (b) a operação a ser realizada; (c) o número maior e (d) o número menor. O procedimento foi semelhante ao de Neef et al. e os resultados demonstraram que após o ensino dos comportamentos precorrentes, os participantes emitiram os comportamentos que solucionavam os problemas e, também, apresentaram soluções para problemas novos.

Os estudos de Levingston et al. (2009) e Neef et al. (2003) permitem sugerir que os com- portamentos precorrentes estabelecidos eram respostas discriminadas das partes que compõem os problemas. Além disso, verifica-se na descrição do procedimento que as sentenças-problema eram lidas pelo participante ou pelo aplicador e que as repostas de construção das operações correspondentes às sentenças-problema eram modeladas. A montagem da operação em correspondência com as sentenças-problema e a operação, bem como a emissão de repostas verbais de leitura desses problemas, pode sugerir que relações condicionais estivessem sendo estabelecidas por meio de pareamento entre esses eventos (sentença-problema impressa, operação e sentença-problema lida/ouvida), de forma semelhante aos procedimentos respondent-type, go/no-go e yes/no (ver descrição em Debert, Matos, \& Andery, 2006; Perez, Campos, \& Debert, 2009). Assim, a construção das operações em correspondência com as sentenças-problema, além das respostas de discriminação de estímulos, podem ser aspectos relevantes para o desenvolvimento do repertório comportamental simbólico que a Matemática envolve e, portanto, fundamental para o resultado positivo observado nos dois estudos relatados aqui.

O estabelecimento de relações condicionais entre diferentes formas de apresentação de problemas aritméticos sobre o desempenho na resolução desse tipo de problema foi investigado por Haydu et al. (2006), as quais sugeriram que o ensino de relações condicionais entre a forma de sentenças-problema, de operação e de balança, pode levar à formação de classes de equivalência e isso pode contribuir para melhorar o desempenho do participante na resolução daquela forma de problema em que ele apresenta desempenho mais baixo. O procedimento mais frequentemente usado para a formação de classes de equivalência consiste em estabelecer duas ou mais relações condicionais com um elemento em comum e testar a emergência das propriedades que definem esse tipo de classe, que segundo Sidman (2000) são: a simetria, a reflexividade e a transitividade. A propriedade de reflexividade é demonstrada quando cada estímulo tem uma relação condicional com um estímulo fisicamente idêntico, ou seja, ao apresentar o estímulo A1 
como modelo, o participante deve selecionar o estímulo de comparação A1, sem que essa resposta tenha sido diretamente reforçada. Essa relação é especificada como A1A1 e as demais, dependendo do número de estímulos por classes, são especificadas A2A2, A3A3, ... AnAn. A propriedade de simetria indica que as funções do estímulo-modelo e o estímulo de comparação são intercambiáveis. Nesse caso, após o ensino, por exemplo, das relações A1B1, A2B2, ... AnBn, devem emergir as relações $\mathrm{B} 1 \mathrm{~A} 1, \mathrm{~B} 2 \mathrm{~A} 2, \ldots$ BnAn, ou seja, ao apresentar o estímulo B1 como estímulo-modelo, o participante deve escolher o estímulo de comparação A1, entre outras opções (A2, A3, ... An). A propriedade de transitividade é demonstrada se após o ensino das relações condicionais A1B1, A2B2, ... AnBn e A1C1, A2C2, ... AnCn, se for observada a emergência das relações B1C1, B2C2, ... BnCn; e C1B1, C2B2, ... $\mathrm{CnBn}$. Para efeito de economia os números das representações alfanuméricas são geralmente omitidos como foi feito a seguir.

Para exemplificar o procedimento de formação de classes de equivalência, pode-se considerar o ensino da relação entre a palavra "dois" (A1) e o algarismo 2 (B1); e o ensino da relação condicional entre o algarismo 2 (A1) e o algarismo romano II (C1). Após o ensino, devem emergir as relações condicionais de reflexividade em que se observa que "dois" será relacionado a "dois" (A1A1), assim como a relação de igualdade entre os demais estímulos; e de simetria observando-se que diante do algarismo 2 , o participante escolherá a palavra "dois" (B1A1); e diante do algarismo romano II será escolhido o algarismo 2 (C1A1). No teste de transitividade deve ser escolhido o algarismo II diante do algarismo 2 (B1C1) e diante do algarismo II escolher o algarismo 2 (C1B1).

No estudo desenvolvido por Haydu et al. (2006), foi investigado se a formação de relações de equivalência entre diferentes formas de apresentação de problemas pode contribuir para melhorar o desempenho na resolução de problemas do mesmo tipo. $\mathrm{O}$ ensino de relações de equivalência visou a formação de nove classes de estímulos equivalentes, formadas por três estímulos cada. Foram utilizados cadernos com balanças impressas, retiradas do software "Arit-Fácil" (Iégas, 2003), operações e sentenças-problemas correspondentes. Esses problemas tinham a incógnita nas três posições $a, b$ e $c$ (por exemplo, $2+5=\mathrm{x} ; 4+\mathrm{x}=8 ; \mathrm{x}+6=10)$, e as sentenças-problema tinham estrutura sintática semelhante as do estudo de Neef et al. (2003), por exemplo, "Chico Bento tinha três peixes, pescou mais um. Quantos peixes Chico Bento tem agora?". Participaram 20 estudantes, de 6 a 7 anos, que cursavam a $1^{\text {a }}$ série do Ensino Fundamental. Eles foram submetidos a três fases do procedimento. No início, os participantes responderam a um pré-teste para o estabelecimento da linha de base e, no final, a um pós-teste. Esses testes eram formados por 45 problemas aritméticos, sendo 15 de cada uma das três diferentes formas de apresentação (operação, balança e sentença-problema) e com a incógnita nas diferentes três diferentes posições $a, b$ e $c$. No pós-teste, os problemas eram semelhantes aos do pré-teste, mas diferiam quanto aos valores numéricos da resposta solução, as quais variavam de 0 a 9 . O procedimento consistiu em ensinar relações condicionais entre as diferentes formas de apresentação dos problemas aritméticos, não tendo sido solicitada a resolução dos problemas, com o uso de patas catálogo. As relações condicionais ensinadas foram AB: problemas na forma de balança (estímulo-modelo) e de operações (estímulos de comparação); AC: problemas na forma de balança (estímulo-modelo) e sentenças-problema (estímulos de comparação). Em cada tentativa de ensino havia sempre um estímulo-modelo em forma de balança e três estímulos de comparação, que podiam ter a forma de operação ou de sentença-problema, dependendo do tipo de tentativa de ensino (ver exemplos nas Figuras 2 e 3 inseridas no método deste estudo). Os estímulos de comparação que não correspondiam ao estímulo-modelo compostos por valores numéricos diferentes, mas com a incógnita ocupando a mesma posição do estímulo-modelo (por exemplo, no caso de o estímulo-modelo ser a balança $\mathrm{x}+6=10$ bal. $^{2}$, os estímulos de comparação eram

2 Neste artigo, as balanças são identificadas pela operação correspondente seguida pela abreviação 
as operações $x+5=8, x+3=7, x+6=10$ ). Após essa fase de ensino, foi aplicado o teste das relações emergentes, com tentativas que verificavam se haviam emergido as relações de simetria (relações BA e CA) e de equivalência (relações BC e CB).

Haydu et al. (2006) verificaram que os participantes formaram as classes de estímulos equivalentes com três diferentes formas de apresentação dos problemas, tendo requerido apenas um bloco de ensino para que esse comportamento emergisse. Ao comparar os dados do pré-teste e do pós-teste, observou-se que a maioria dos participantes apresentou aumento na porcentagem de acerto no pós-teste, independentemente da posição da incógnita e do tipo de problema. As autoras concluíram que o estabelecimento de relações de equivalência entre as diferentes formas de problemas apresentados com incógnitas nas diferentes posições permitiu que os alunos do Ensino Fundamental melhorassem o desempenho na resolução de problemas aritméticos.

Os resultados relatados por Haydu et al. (2006), Levingston et al. (2009), Neef etal. (2003), permitem sugerir que intervenções baseadas nos princípios de análise do comportamento são formas econômicas e efetivas de ensino. Além disso, deve-se considerar que diferentes populações podem ser beneficiadas por esse tipo de intervenção, como participantes com desenvolvimento atípico ou com lesões neurológicas causadas de diferentes naturezas, bem como idosos com perda de funções cognitivas ou ainda aqueles que não tenham sido previamente alfabetizados.

O desempenho na resolução de problemas em forma de sentenças-problema foi analisado no estudo de Allain, Kauffmann, Dubas, Berrut e Le Gall (2007), por meio da comparação do desempenho de 18 jovens, 18 adultos e 18 idosos na resolução de problemas com diferentes graus de dificuldade. Os níveis de dificuldade eram dos tipos que envolviam duas operações, cujo algoritmo de resolução envolvia $\mathrm{a}+(\mathrm{a}+\mathrm{b})$; três operações, cujo algoritmo era $a+(a-b)+(a+c)$; e

"Bal." da palavra "Balança" quando mencionadas no texto. As representações gráficas das balanças estão na Tabela 2 da seção do Método. quatro operações, cujo algoritmo era $a+(a-b)$ $+\{[a+(a-b)]-c\}$. Além disso, foram testados quatro problemas insolúveis. A comparação dos dados feita por meio de tratamento estatístico revelou que os idosos resolveram significativamente menos problemas dos três níveis de dificuldade do que os participantes jovens, e resolveram significativamente menos problemas do nível que envolvia quatro operações do que os adultos. Eles, no entanto, foram capazes de descartar os problemas insolúveis. O desempenho dos participantes jovens e adultos não diferiu em relação a qualquer nível de complexidade. Esses resultados permitem sugerir ser relevante investigar o processo envolvido na perda da habilidade de resolução de problemas aritméticos e também de se procurar encontrar métodos que permitam reduzir a perda dessa capacidade ou até de recuperá-la.

A presente pesquisa visou replicar o estudo de Haydu et al. (2006), porém, em vez de trabalhar com crianças, avaliou-se tal procedimento com adultos e idosos em processo de alfabetização. A questão formulada é se o ensino de relações condicionais entre diferentes formas de apresentação dos problemas aumenta o desempenho na resolução de problemas aritméticos, principalmente, daquele tipo que o participante apresenta menor desempenho inicial. Assim, o objetivo foi investigar se a formação de relações de equivalência entre diferentes formas de apresentação de problemas aritméticos melhora o desempenho na resolução de problemas aritméticos.

\section{Método}

\section{Participantes}

Participaram do estudo quatro mulheres, com idade entre 37 anos e 71 anos, em processo de alfabetização, que frequentavam uma escola de periferia (Educação para Jovens e Adultos - EJA) e que foram indicadas pela professora para a pesquisa porque não estavam aprendendo a resolução de problemas aritméticos. As participantes frequentavam a escola havia mais de 3 anos (ver Tabela 1), mas elas não haviam aprendido a ler fluentemente, podendo ser consideradas pré-alfabetizadas. 
Tabela 1

Características dos Participantes quanto à Idade e Tempo de Frequência da EJA em Anos

\begin{tabular}{ccc}
\hline Participantes & Idades & Tempo de frequência da EJA \\
\hline P1 & 71 & 4 anos e 6 meses \\
P2 & 37 & 3 anos e 1 meses \\
P3 & 67 & 3 anos e 6 meses \\
P4 & 55 & 4 anos \\
\hline
\end{tabular}

\section{Materiais e Situação Experimental}

Para a coleta de dados da linha de base (préteste) e para o pós-teste foram utilizados cadernos com 45 folhas de $14 \times 17 \mathrm{~cm}$. Em cada página do caderno havia um problema aritmético impresso, de uma das três formas de apresentação: sentençaproblema, balança e operação. No caderno havia ao todo 45 problemas, sendo 15 na forma de operação, 15 na forma de sentença-problema e 15 na forma de balanças (ver Tabela 2), cuja sequência foi modificada para a realização do pós-teste. Dos 15 problemas de cada tipo, havia cinco com cada uma das diferentes posições de incógnita $a, b$, e $c$, em sequência aleatorizada. As imagens dos problemas em forma de balança foram retiradas do software "Arit-Fácil" (Iégas, 2003), com autorização da autora. Exemplos de imagens das balanças estão na Figura 1 .

Para o procedimento de ensino das relações condicionais e os testes das relações emergentes foram usadas pastas-catálogo, contendo embalagens plásticas dentro das quais foram inseridas folhas de papel branco, cada uma com uma tentativa de ensino ou de teste. Para o ensino, as folhas eram separadas em duas partes (ver exemplos nas Figuras 2 e 3) com o estímulo-modelo em forma de balança (A) na parte superior, sendo eles: balanças com incógnita na posição $a$ $(x+5=8$ bal., $x+3=7$ bal., $x+6=10$ bal.), na posição $b(4+\mathrm{x}=7$ bal., $5+\mathrm{x}=8$ bal., $6+\mathrm{x}=6$ bal. $)$ e na posição $c(3+6=x$ bal., $4+2=x$ bal., $8+1=x$ bal.). $A$ parte inferior era subdivida em três partes iguais, contendo os estímulos de comparação, que eram operações (B) ou sentenças-problema (C) a depender do tipo de teste (ver Figuras 2 e 3). Esses problemas eram compostos por valores numéri- cos diferentes, mas com a incógnita ocupando a mesma posição do estímulo-modelo. Para os testes das relações emergentes, as folhas tinham na parte superior os estímulos que correspondiam ao tipo de teste a ser executado, podendo ser uma balança (A) quando testadas as relações de linha de base, ou uma operação (B) e/ou uma sentença-problema (C) nos demais testes. Os estímulos de comparação também variavam em forma de acordo com o tipo de relação testada. Os problemas envolviam algarismos entre 0 e 9 , sendo que o valor máximo do resultado de um problema era 10. No total, foram usados nove problemas, três para cada forma de apresentação, sendo um para cada posição de incógnita.

No treino preparatório, foram usados seis cartões medindo $15 \times 17 \mathrm{~cm}$ com problemas em forma de balança impressos. Esses problemas eram semelhantes aos que eram utilizados nas fases de ensino, mas com valores diferentes.

A pesquisa foi realizada na escola das participantes (EJA) em uma sala de aula desocupada, livre de barulho e interrupções. Durante toda a coleta, experimentadora e participante permaneceram sentadas uma ao lado da outra, em carteiras escolares.

\section{Procedimento}

A realização do estudo iniciou com as experimentadoras fazendo uma explanação dos objetivos da pesquisa e do procedimento às participantes selecionadas previamente pela professora da escola. O Termo de Consentimento Livre e Esclarecido (aprovado pelo Comitê de Ética em Pesquisa da Instituição das autoras) foi lido para elas, uma vez que não tinham a habilidade de 
Tabela 2

Sequências dos Problemas em Forma de Operação, Sentença e Balança (representados pela operação correspondente mais a abreviação bal.) no Pré-Teste e no Pós-Teste

\begin{tabular}{llll}
\hline $\mathrm{N}^{\mathrm{o}}$ & Operação & Sentença & Balança \\
\hline & Pré-teste
\end{tabular}

$\begin{array}{llll}1 & \mathrm{x}+3=5 & \text { Quantos pirulitos Cebolinha ganhou? Ele não tinha nenhum e ficou com nove. } & \mathrm{x}+6=6 \mathrm{bal} . \\ 2 & 8+\mathrm{x}=10 & \text { Bidu tinha seis cubos e ganhou três. Com quantos ficou? } & 3+5=\mathrm{x} \text { bal. } \\ 3 & 2+6=\mathrm{x} & \text { Quantos bonés Cascão ganhou? Ele tinha dois e ficou com oito. } & 4+\mathrm{x}=6 \mathrm{bal} . \\ 4 & 1+8=\mathrm{x} & \text { Quantas bolas Bidu tinha? Ele ganhou oito e ficou com nove. } & 5+2=\mathrm{x} \text { bal. } \\ 5 & \mathrm{x}+1=2 & \text { Mônica tinha três biscoitos e ganhou três. Com quantos ficou? } & 3+\mathrm{x}=9 \mathrm{bal} . \\ 6 & 8+\mathrm{x}=8 & \text { Quantos doces Mônica tinha? Ela comprou dois e ficou com sete. } & 4+4=\mathrm{x} \text { bal. } \\ 7 & \mathrm{x}+9=10 & \text { Cebolinha tinha três laranjas e ganhou sete. Com quantas ficou? } & \mathrm{x}+8=10 \mathrm{bal} . \\ 8 & 7+3=\mathrm{x} & \text { Quantos livros Cascão tinha? Ele ganhou cinco e ficou com cinco. } & 6+\mathrm{x}=7 \mathrm{bal} . \\ 9 & 5+5=\mathrm{x} & \text { Chico Bento tinha cinco lápis e ganhou um? Com quantos ficou? } & 2+2=\mathrm{x} \text { bal. } \\ 10 & \mathrm{x}+2=9 & \text { Quantas pipas Chico Bento ganhou? Ele tinha uma e ficou três. } & 2+\mathrm{x}=10 \mathrm{bal} . \\ 11 & 3+\mathrm{x}=5 & \text { Quantos ossos Bidu ganhou? Ele tinha quatro e ficou com seis. } & \mathrm{x}+6=9 \mathrm{bal} . \\ 12 & \mathrm{x}+6=8 & \text { Quantos balas Magali ganhou? Ela tinha cinco e ficou com dez. } & \mathrm{x}+3=4 \text { bal. } \\ 13 & 2+\mathrm{x}=6 & \text { Magali tinha uma flor e ganhou uma. Com quantas ficou? } & 3+1=\mathrm{x} \text { bal. } \\ 14 & 4+3=\mathrm{x} & \text { Quantos lápis Chico Bento ganhou? Ele tinha três e ficou com seis. } & 7+\mathrm{x}=9 \text { bal. } \\ 15 & 5+\mathrm{x}=7 & \text { Quantas petecas Magali tinha? Ela ganhou duas e ficou com três. } & \mathrm{x}+4=8 \text { bal. }\end{array}$

\begin{tabular}{|c|c|c|c|}
\hline \multicolumn{4}{|c|}{ Pós-teste } \\
\hline 1 & $2+6=x$ & Bidu tinha seis cubos e ganhou três. Com quantos ficou? & $4+4=x$ bal. \\
\hline 2 & $x+1=2$ & Quantos doces Mônica tinha? Ela comprou dois e ficou com sete. & $2+x=10$ bal. \\
\hline 3 & $1+8=\mathrm{x}$ & Quantos pirulitos Cebolinha ganhou? Ele não tinha nenhum e ficou com nove. & $4+x=6$ bal. \\
\hline 4 & $x+3=5$ & Cebolinha tinha três laranjas e ganhou sete. Com quantas ficou? & $3+1=x$ bal. \\
\hline 5 & $x+2=9$ & Quantos livros Cascão tinha? Ele ganhou cinco e ficou com cinco. & $6+x=7$ bal. \\
\hline 6 & $7+3=x$ & Quantas pipas Chico Bento ganhou? Ele tinha uma e ficou três. & $x+3=4$ bal. \\
\hline 7 & $8+x=10$ & Quantos ossos Bidu ganhou. Ele tinha quatro e ficou com seis. & $\mathrm{x}+6=6$ bal. \\
\hline 8 & $x+6=8$ & Mônica tinha três biscoitos e ganhou três. Com quantos ficou? & $7+x=9$ bal. \\
\hline 9 & $x+9=10$ & Quantos balas Magali ganhou? Ela tinha cinco e ficou com dez. & $3+x=9$ bal. \\
\hline 10 & $3+x=5$ & Magali tinha uma flor e ganhou uma. Com quantas ficou? & $\mathrm{x}+8=10$ bal. \\
\hline 11 & $2+x=6$ & Quantas bolas Bidu tinha? Ele ganhou oito e ficou com nove. & $\mathrm{x}+4=8 \mathrm{bal}$ \\
\hline 12 & $4+3=x$ & Quantas petecas Magali tinha? Ela ganhou duas e ficou com três. & $x+6=9$ bal. \\
\hline 13 & $5+5=x$ & Quantos bonés Cascão ganhou? Ele tinha dois e ficou com oito. & $5+2=x$ bal. \\
\hline 14 & $5+x=7$ & Chico Bento tinha cinco lápis e ganhou um? Com quantos ficou? & $2+2=x$ bal. \\
\hline 15 & $8+x=8$ & Quantos lápis Chico Bento ganhou? Ele tinha três e ficou com seis. & $3+5=x$ bal. \\
\hline
\end{tabular}




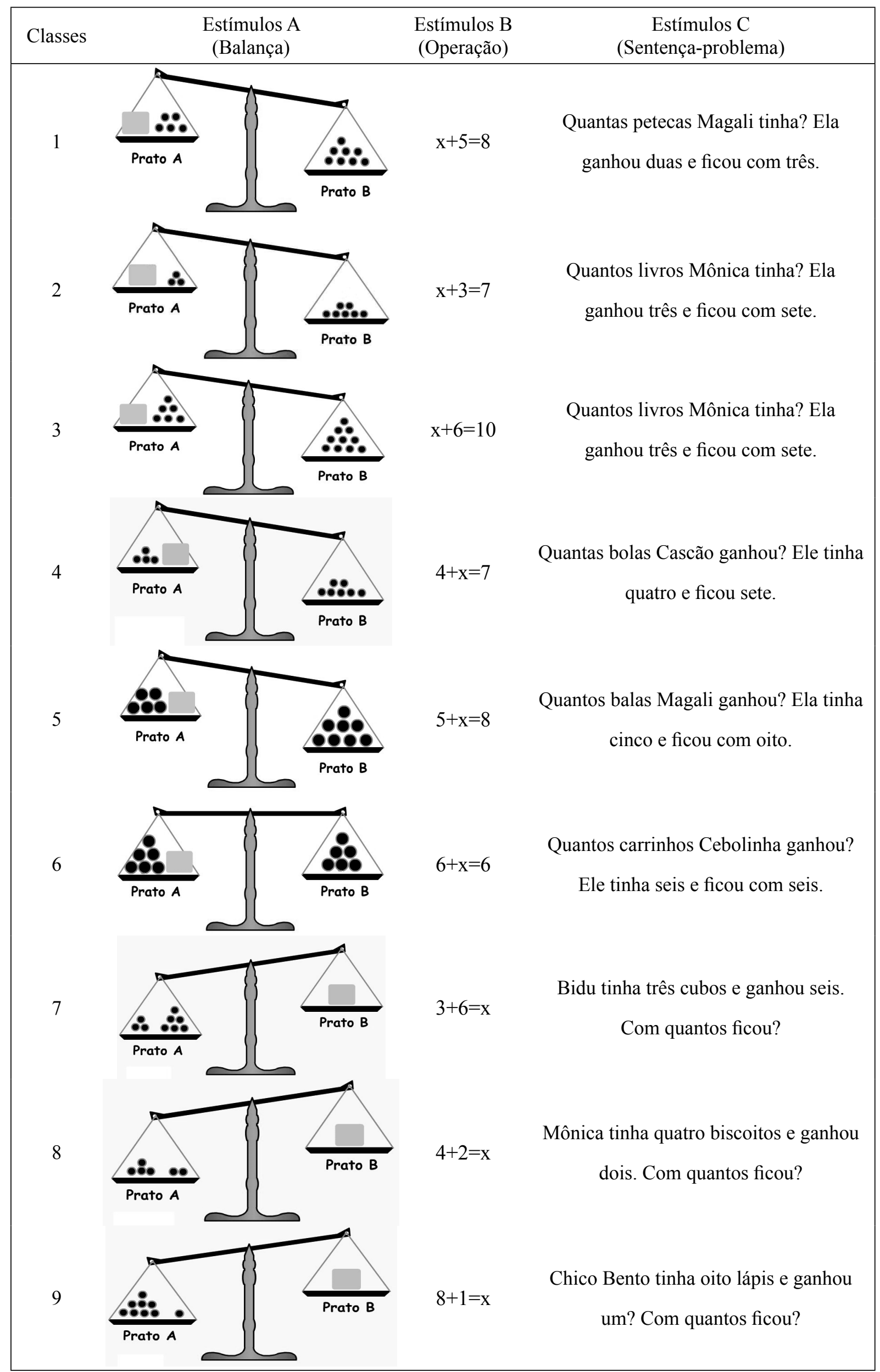

Figura 1. Conjuntos de estímulos em forma de balança (A), de operação (B) e de sentença-problema. 
fazê-lo e, em seguida, foi solicitada a assinatura do termo. As quatro participantes consentiram em participar do estudo.

A coleta de dados teve duração de duas semanas. As sessões foram planejadas para durarem, no máximo, uma hora cada. Foram realizadas duas ou três sessões individuais por semana com cada participante, sempre em horário no qual elas estavam na escola.

Pré-Teste. A experimentadora ensinava inicialmente à participante como responder diante de um problema apresentado no caderno antes da realização do pré-teste, o qual continha problemas representados nas três diferentes formas: balança, sentença-problema e operação (ver Tabela 2). As instruções iniciais para o pré-teste foram: "Observe no caderno problemas representados em três diferentes formas: na forma de equação, de sentença e na forma de uma balança. Agora, eu vou explicar um de cada vez, para que você possa resolver todos os problemas".

Inicialmente, as participantes receberam instrução para a resolução dos problemas em forma de equação, seguida pela instrução para os problemas em forma de sentença-problema e depois para os problemas em forma de balança. Em seguida, foram dadas instruções específicas para cada um dos três primeiros problemas (um de cada tipo), as quais foram iguais às apresentadas pelas experimentadoras no estudo de Haydu et al. (2006). Como não foi critério de seleção que as participantes soubessem ler e como não o faziam fluentemente, foi necessário que a experimentadora lesse para elas. Logo após, a experimentadora solicitava à participante que verbalizasse a respostas dos problemas subsequentes, não havendo consequências específicas para as respostas. $\mathrm{O}$ registro das respostas foi feito pela própria experimentadora em folhas de registro com espaços para assinalar qual a resposta apresentada pela participante.

Familiarização com os Estímulos. Durante a realização do pré-teste, verificou-se a necessidade de familiarização das participantes com os símbolos matemáticos de adição e equidade, assim como as diferentes formas de resoluções das operações matemáticas, de acordo com a posição da incógnita ( $a, b$ e $c$ ). Assim, de forma semelhante ao que foi feito no estudo desenvolvido por Haydu et al. (2006), foi planejada a fase de familiarização.

No caso da operação, foi explicado às participantes que esse problema poderia ser apresentado tanto na vertical como na horizontal. Pedia-se para que a participante escrevesse como estava acostumada a resolver um problema aritmético. Todas estruturaram a operação na vertical, colocando as parcelas uma em baixo da outra e o total embaixo de um traço e, assim, era explicada a correspondência dos termos e símbolos na operação representada na horizontal. Dizia-se que o termo superior na operação por ela representada correspondia ao primeiro termo da operação na horizontal (ou seja, era o que vinha antes do sinal de mais). O sinal de mais representava uma adição, uma soma. $\mathrm{O}$ termo intermediário na operação correspondia ao segundo termo na operação horizontal (ou seja, aquele que vinha logo após o sinal de adição ou mais). O "traço" correspondia ao sinal de igual (dois tracinhos) e o número que ficava abaixo do "traço" correspondia ao número que seguia o sinal de igual e significava o resultado da soma, o total. Também foi explicado que as balanças desenhadas eram similares às balanças encontradas antigamente em lojas e vendas e que funcionavam com pesos. Em um dos pratos da balança havia os dois primeiros termos e no outro prato o resultado da soma desses termos. O sinal de igual significava que os pratos da balança deveriam ficar na mesma altura (se equilibrar), ou seja, deveriam conter a mesma quantidade de pesos. Após tais explicações foram apresentados os nove problemas selecionados para essa fase de familiarização.

Ensino das Relações Condicionais entre Estímulos. Para o ensino das relações condicionais entre as diferentes formas de apresentação dos problemas aritméticos, foram apresentados problemas na forma de balança como estímulo-modelo (A). Os estímulos de comparação foram problemas nas formas de operação (B) ou de sentença-problema (C), dependendo do tipo de relação a ser ensinada (relação $\mathrm{AB}$ e relação $\mathrm{AC}$ ). Dois exemplos de tentativas de treino estão representados nas Figuras 2 e 3. 


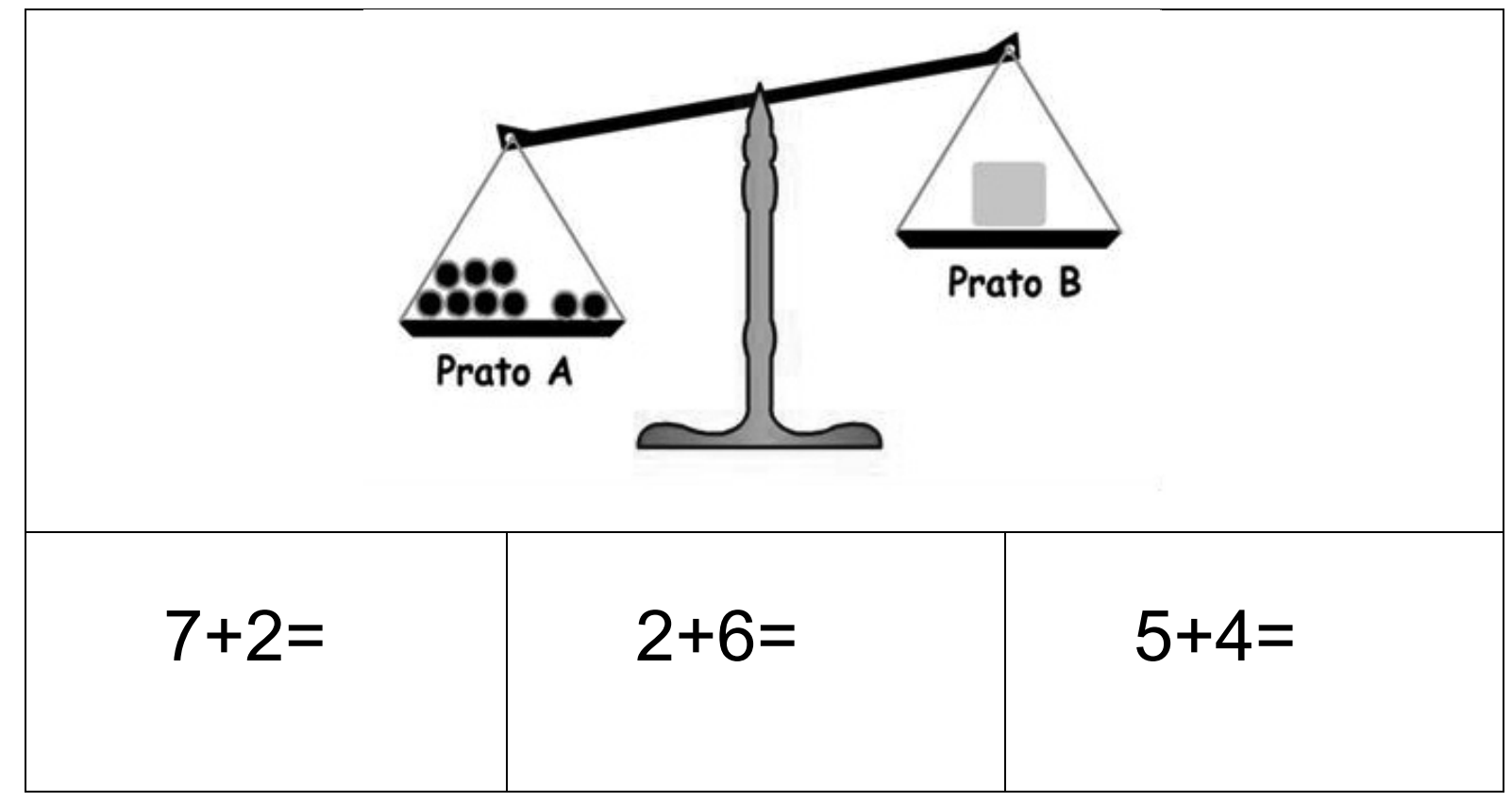

Figura 2. Representação de uma folha do material de ensino, contendo uma tentativa de ensino da relação condicional AB.

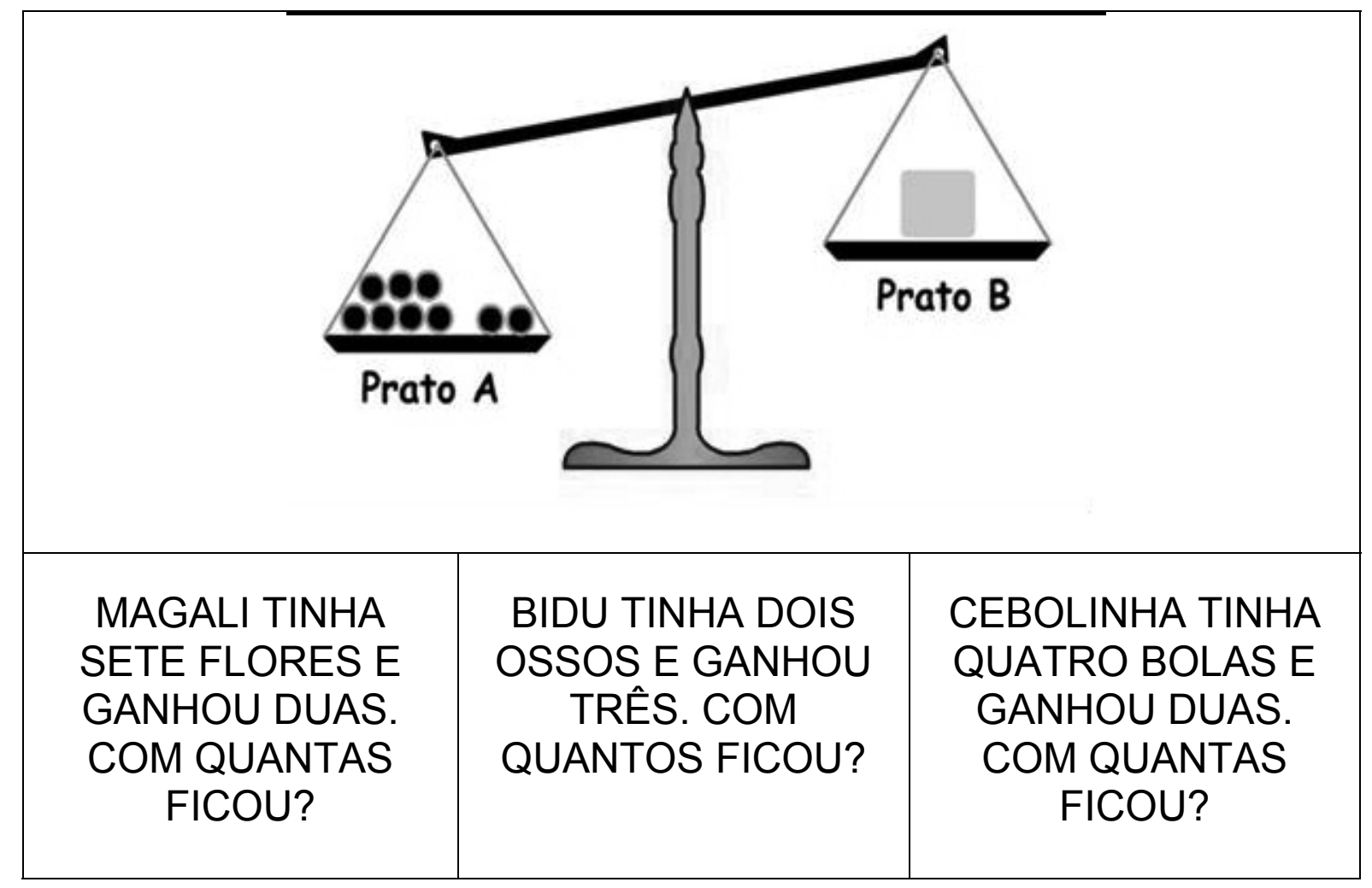

Figura 3. Representação de uma folha do material de ensino, contendo uma tentativa de ensino da relação condicional AC. 
O ensino foi realizado por meio do procedimento de escolha de acordo com o modelo (matching to sample-MTS). Foram realizadas, ao todo, 54 tentativas de discriminação condicional simultânea. Em cada tentativa havia um estímulo-modelo e três estímulos de comparação, sendo que apenas um deles apresentava os mesmos dados que o estímulo-modelo. Os outros dois apresentavam dados diferentes, mas com a incógnita na mesma posição que a do estímulo-modelo.

$\mathrm{Na}$ primeira tentativa, foram dadas as seguintes instrução de como responder. Essas instruções eram:

Você pode observar que esta folha tem um problema na parte de cima e três na parte de baixo. Observe e fale 'este aqui' para mim, ao apontar qual dos problemas da parte de baixo quer dizer a mesma coisa que o problema da parte de cima. Você não precisa mais dizer qual é a solução do problema.

Nove problemas (estímulo-modelo) diferentes eram apresentados para o ensino das relações condicionais $\mathrm{AB}$ e $\mathrm{AC}$, sendo um mesmo estímulo-modelo repetido três vezes, enquanto os estímulos de comparação eram alternados nas três possíveis posições. As participantes que não atingiam no mínimo $90 \%$ de acertos (49 das 54 tentativas) repetiam as 54 tentativas de ensino, na mesma ordem e na mesma seção dentro do limite de 1 hora. Um critério de no máximo três repetições foi estabelecido para o encerramento do procedimento. As respostas corretas e incorretas foram seguidas de consequências diferenciais, informando se a resposta estava correta ou incorreta ("Você acertou" ou "Você errou").

Teste das Relações Emergentes. Antes da realização dos testes, a experimentadora informava à participante que, durante esta etapa, ela deveria responder às tentativas apresentadas de acordo com o que ela aprendera na etapa anterior, mas ela não seria informada se a resposta estava correta ou incorreta, por se tratar de um teste. Primeiro, foi aplicado o teste das relações de linha de base (AB e AC), em seguida, o teste de simetria (BA e CA) e, por fim, o teste de equivalência (BC e $\mathrm{CB}$ ). Foram apresentadas nove tentativas de cada uma das relações de linha de base $\mathrm{AB}$ e $\mathrm{AC}$, nove de cada relação de simetria BA e CA e nove tentativas de cada uma das relações de transitividade $\mathrm{BC}$ e $\mathrm{CB}$, totalizando 54 tentativas. Esse teste foi realizado no final da sessão de treino, compondo um bloco de tentativas.

Pós-Teste. O pós-teste foi composto por 45 problemas aritméticos, apresentados na forma de balança, operação e sentença-problema, da mesma forma como no pré-teste. Os problemas utilizados no pós-teste foram os mesmos do pré-teste, mas em sequencia diferente (Ver Tabela 2). Esse teste foi realizado na mesma sessão que o treino, após um breve intervalo para descanso.

\section{Resultados}

As quatro participantes concluíram todas as etapas do procedimento (atingindo o critério de no máximo três repetições dos blocos de treino), apesar de não terem conseguido ler as sentenças-problema, requerendo para isso auxílio da experimentadora. Os resultados analisados referem-se ao desempenho individual das participantes, tendo-se comparado o desempenho no pré e pós-teste. Na Figura 4 estão os resultados do desempenho geral das participantes nos dois testes, na qual se verificar que todas as participantes apresentaram um aumento acentuado na porcentagem de acertos ao se comparar o pré e pós-testes. A única participante que não atingiu $100 \%$ de acertos no pós-teste foi P1, ficando com $93,3 \%$ de acertos, o que corresponde a três erros, conforme especificado a seguir. A participante que apresentou a maior diferença entre os dois testes foi $\mathrm{P} 4$, que passou de $35,55 \%$ e acertos para $100 \%$.

Nas Figuras 5, 6, 7 e 8 podem ser visualizadas as porcentagens de acertos de cada participante (P1, P2, P3 e P4, respectivamente) no pré-teste e no pós-teste, considerando a posição da incógnita e a forma de apresentação dos problemas. Verifica-se nessas figuras que, de forma geral, o melhor desempenho das participantes 


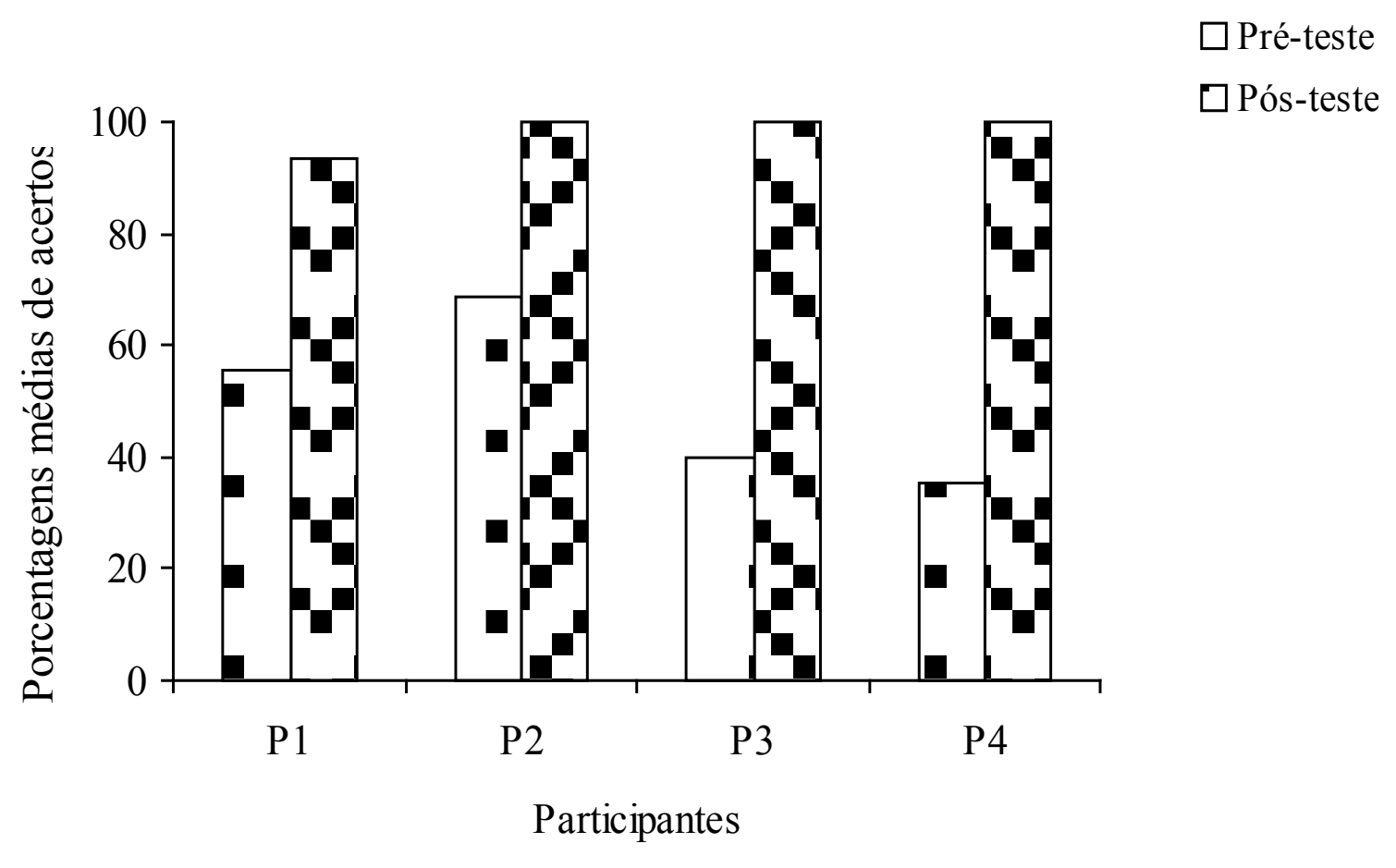

Figura 4. Porcentagens médias de acertos no pré-teste e no pós-teste na resolução de problemas nas formas de apresentação de operação, sentença-problema e balança.

no pré-teste foi nos problemas com a incógnita na posição $c$. As porcentagens de acertos nesse tipo de problema foi igual ou superior a $88,9 \%$ em todos os tipos de problemas, com quatro exceções: P1 nas sentenças-problema $(44,4 \%$ de acertos) e nos problemas em forma de balança (66,6\% de acertos); P2 nas sentenças-problema (66,6\% de acertos); $\mathrm{P} 3$ nos problemas em forma de balança (22,2\% de acertos). Ainda em relação ao pré-teste, verifica-se que as quatro participantes apresentam porcentagens de acertos iguais ou superiores na resolução de sentenças-problema do que nos problemas em forma de operação, considerando as posições de incógnita $a$ e $b$. Com relação à posição da incógnita, as menores porcentagens de acertos foram apresentadas nos problemas com a incógnita na posição $a$ e/ou $b$, em comparação à posição $c$, na maioria dos casos.

$\mathrm{O}$ ensino das relações condicionais foi repetido até os participantes atingirem no mínimo $90 \%$ de acertos nessa etapa, tendo-se observado que todas as quatro participantes atingiram $100 \%$ de acertos em no máximo três blocos de ensino. Os testes das relações de linha de base, e das relações emergentes de simetria e de equivalência não foram repetidos e nessa apresentação dos testes verificou-se que três das quatro participantes apresentaram $100 \%$ de acertos em todos os testes (P2, P3 e P4). P1 apresentou $88,9 \%$ de acertos no teste de simetria (Relação BA) e $77,7 \%$ no teste de equivalência (Relação $\mathrm{CB}$ e $\mathrm{BC})$.

No pós-teste, observa-se nas Figuras 5, 6, 7 e 8 que as participantes apresentaram aumento nas porcentagens de acertos em relação ao pré-teste, com uma exceção. Três participantes (P2, P3 e P4) atingiram $100 \%$ de acertos em todas as diferentes formas de apresentação dos problemas, independente da posição da incógnita. P1 apresentou no pré-teste desempenho igual a $100 \%$ em problemas na forma de operação com incógnita na posição $c$, mas a porcentagem de acertos foi menor no pós-teste $(88,9 \%)$. Essa porcentagem corresponde a um erro. Verifica-se ainda que essa participante apresentou um erro no pós-teste nos problemas em forma de balança com incógnita na posição $b$ e um erro nas sentenças-problema com incógnita na posição $a$ (88,9\% de acertos). 


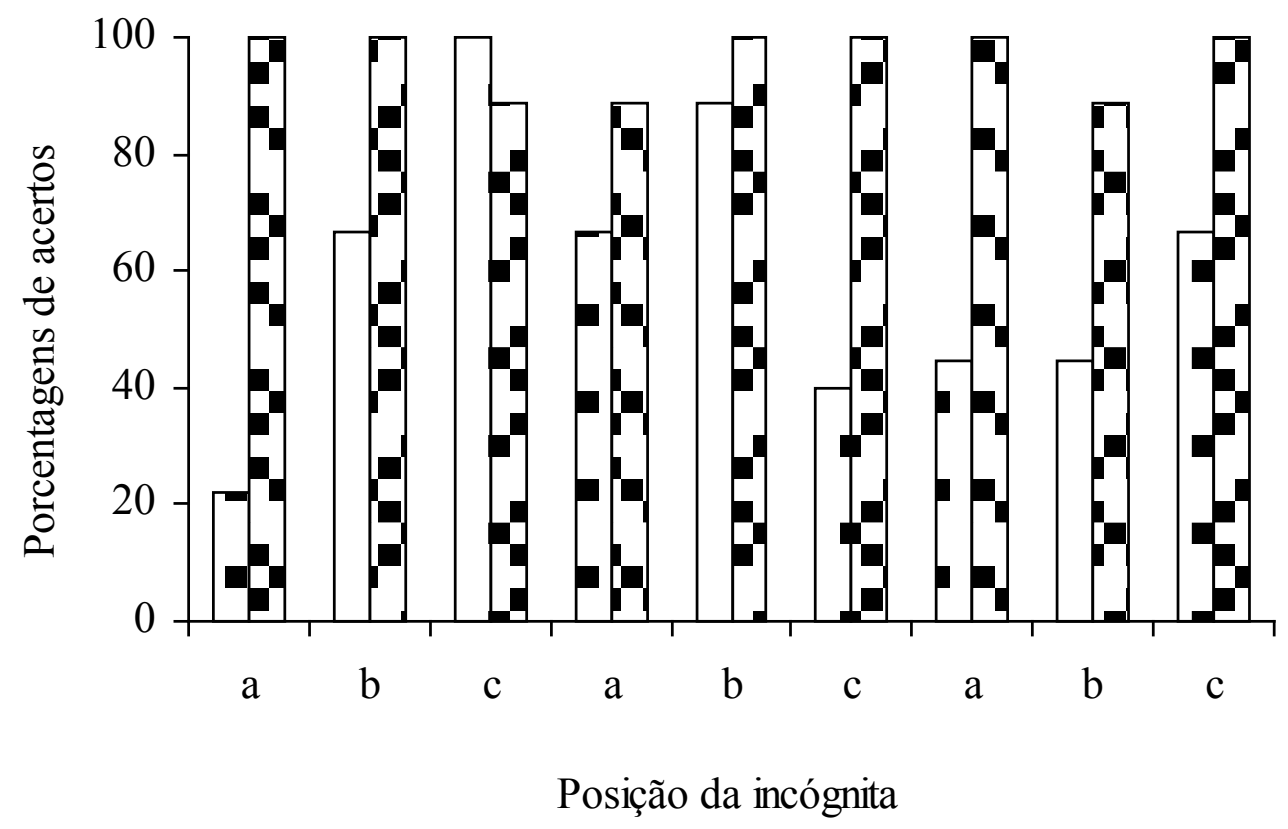

Figura 5. Porcentagens de acertos da P1 nos problemas em forma de operação, balança e sentença-problema, considerando a posição da incógnita nas posições a, b e c.

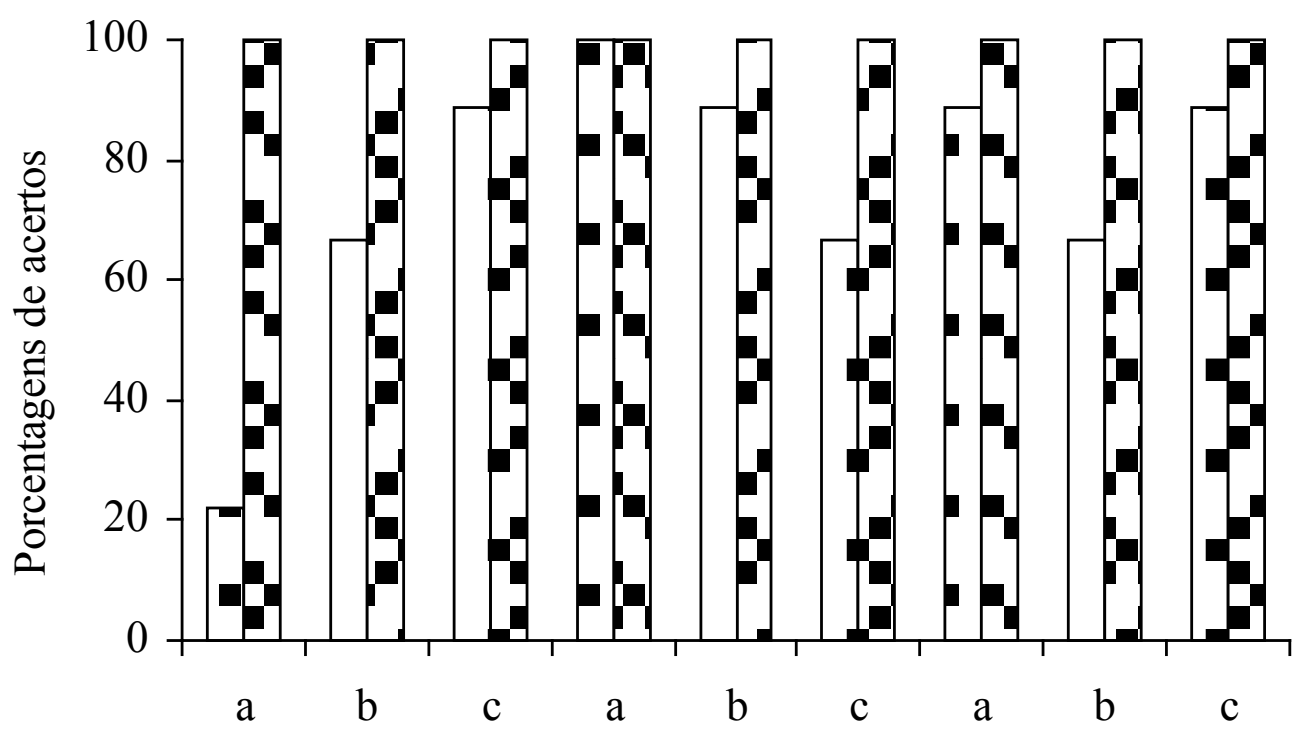

\section{Posição da incógnita}

Figura 6. Porcentagens de acertos da $P 2$ nos problemas em forma de operação, balança e sentença-problema, considerando a posição da incógnita nas posições a, b e c . 


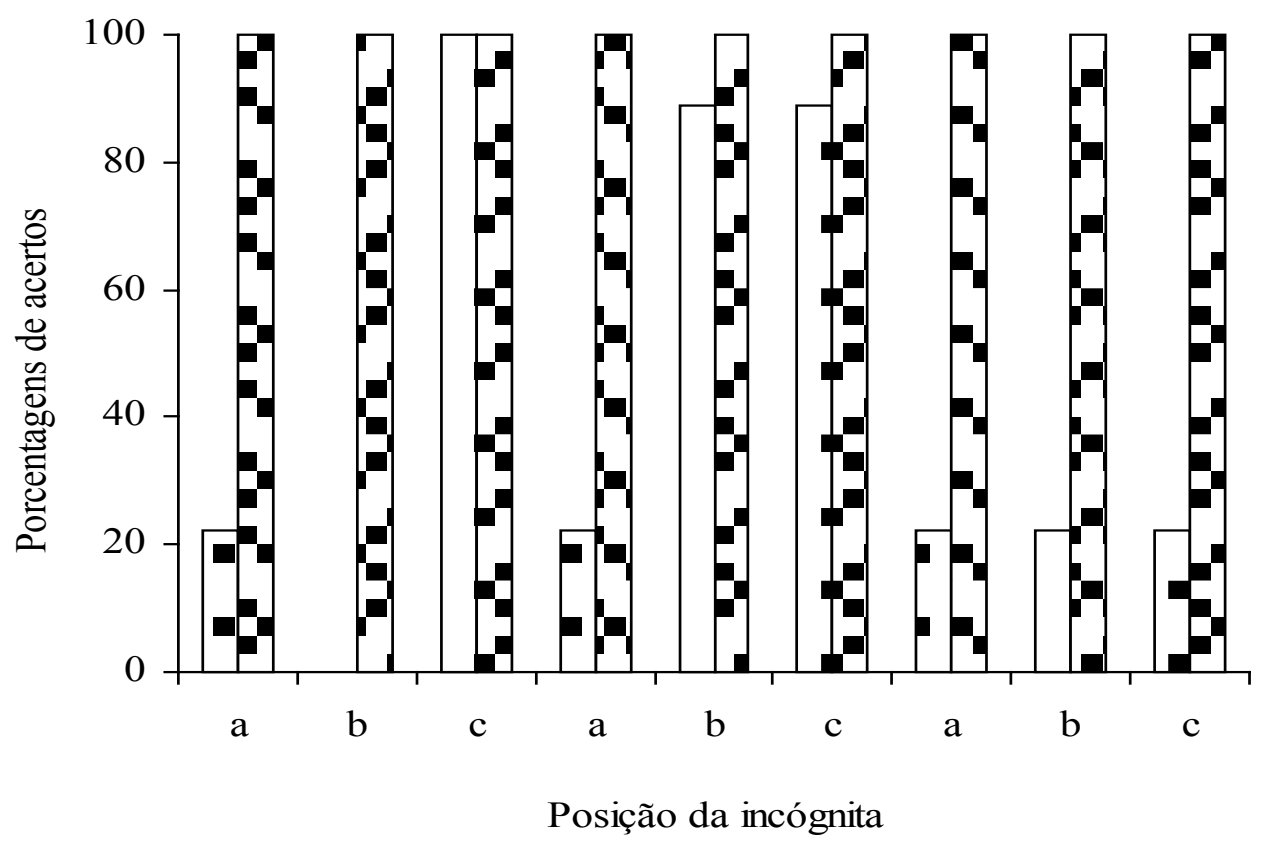

Figura 7. Porcentagens de acertos da P3 nos problemas em forma de operação, balança e sentença-problema, considerando a posição da incógnita nas posições a, b e c.

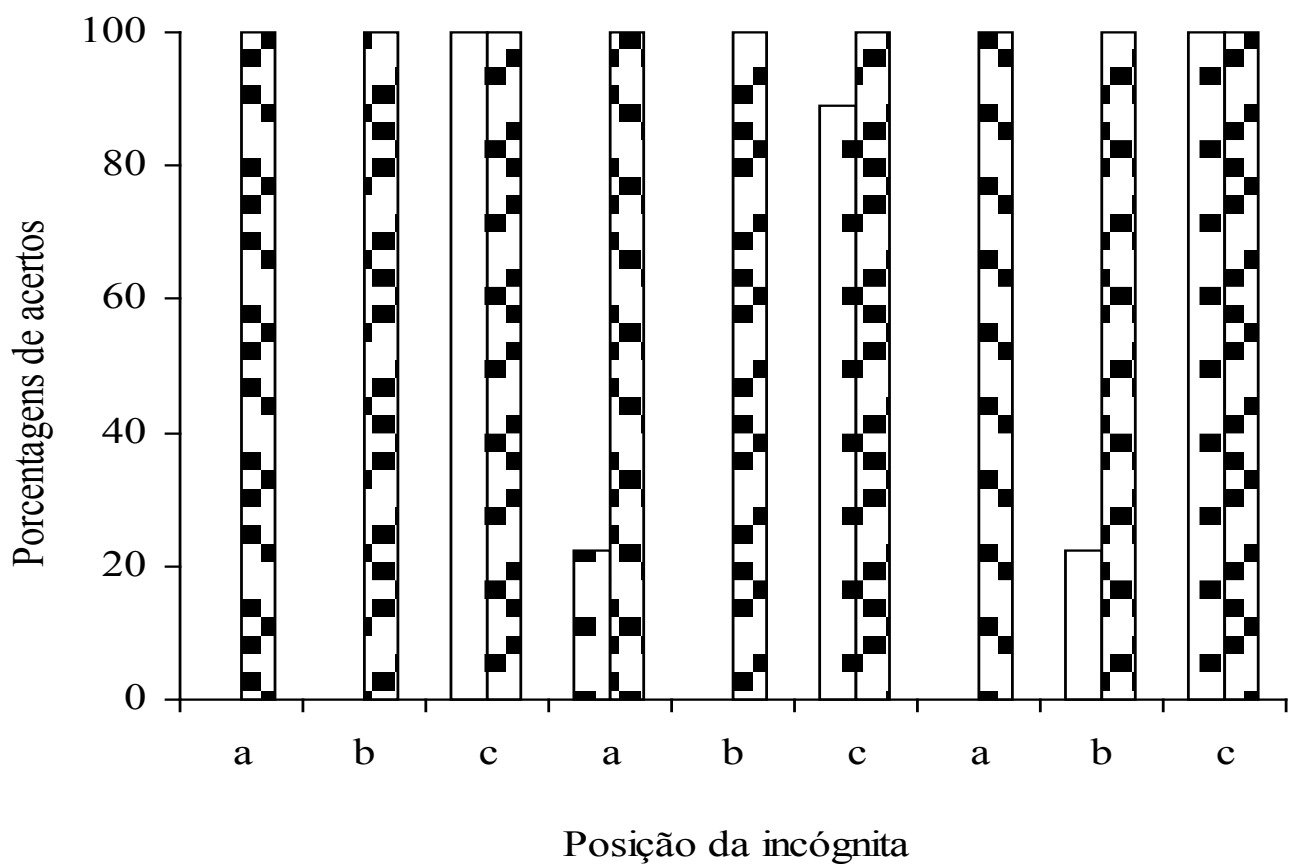

Figura 8. Porcentagens de acertos da $\mathbf{P} 4$ nos problemas em forma de operação, balança e sentença-problema, considerando a posição da incógnita nas posições a, b e c. 


\section{Discussão}

O presente estudo visou replicar aquele desenvolvido por Haydu et al. (2006), para investigar se a formação de relações de equivalência entre diferentes formas de apresentação de problemas aritméticos melhora o desempenho na resolução de problemas. Os resultados permitem constatar que todas as participantes formaram classes de equivalência e todas apresentaram um aumento na porcentagem geral de acertos ao se comparar os dados do pré-teste com os do pós-teste. Os resultados permitiram observar também que as participantes do presente estudo apresentaram diferenças maiores ao se comparar os dados do pré-teste com o pós-teste do que aqueles apresentados pelos participantes do estudo de Haydu et al. No presente estudo, a maior diferença entre os dois testes foi de P4 (55 anos), que após os procedimentos de ensino preparatório e o de ensino das relações condicionais, com a demonstração a formação das classes de equivalência, passou de $0 \%$ a $100 \%$ de acertos na resolução de problemas em forma de operação com incógnita nas posições $a$ e $b$, nas sentenças-problema com posição de incógnita $b$, e nos problemas em forma de balança com incógnita na posição $a$. A única participante que não atingiu um índice geral de $100 \%$ de acertos no pós-teste foi P1 (71 anos), que apresentou um erro na resolução de problemas em forma de operação com incógnita na posição $c$, um nos problemas em forma de balança com incógnita na posição $b$ e um nas sentenças-problemas com incógnita na posição $a$. No estudo de Haydu et al. apenas um dos sete participantes apresentou um índice geral de acertos de 100\% no pós-teste e dois apresentaram porcentagens acima de $90 \%$. Os demais participantes apresentaram valores inferiores a $75 \%$ de acertos. Uma das razões para essa diferença pode estar no tipo de contexto motivacional das duas escolas em que os estudos foram realizados. Frequentar a EJA é algo que os alunos fazem por opção pessoal, provavelmente sob o controle de reforçadores naturais, isto é, os reforçadores produzidos pela aprendizagem. Os alunos do Ensino Fundamental, possivelmente estejam mais sob o controle de reforços sociais e/ou arbitrários que não a própria aprendizagem. Além disso, os participantes do estudo de Haydu et al. frequentavam uma escola onde não havia um currículo pré-estabelecido e as contingências de ensino eram arranjadas de acordo com o interesse dos alunos. Participar das sessões experimentais pré-programadas pelas experimentadoras, nesse caso, era discrepante em relação ao tipo de atividade e da forma de programação de atividades que as crianças realizavam com frequência na escola.

Outro aspecto que diferiu com relação aos resultados dos estudos de Haydu et al. (2006) e os do presente estudo está relacionado ao fato de que as quatro participantes apresentam, no pré-teste, porcentagens de acertos iguais ou superiores na resolução de sentenças-problema com incógnitas na posição $a$ e $b$ do que nos problemas em forma de operação. Em Haydu et al., menos da metade dos participantes apresentaram porcentagens de acertos superiores ou iguais na resolução das sentenças-problema ao se fazer essa comparação. No estudo de Henklain e Carmo (2013b), apenas dois dos oito participantes apresentaram porcentagens de acertos maiores no pré-teste em forma de operação do que de sentenças-problema. Essa diferença possivelmente se deva ao fato de que as participantes do presente estudo já estavam habituadas a resolver problemas que lhes são apresentados, em seu cotidiano, na forma de sentenças verbalizadas ao fazerem compras e calcularem quanto terão que pagar ou receber de troco. No entanto, problemas em forma de operações não são apresentados a elas com frequência ou até nunca ocorrem. Outro fator que, provavelmente, facilitou a resolução dos problemas das participantes foi o fato de a pesquisadora ter lido as sentenças-problema para elas, eliminando possíveis erros de leitura. No estudo de Haydu et al., foram lidas somente as palavras que as crianças não conseguiram ler.

É preciso ressaltar ainda que os ganhos no desempenho dos participantes podem também ser justificados pela sessão de familiarização, na qual as participantes receberam instruções a respeito das diferentes formas de resolução dos problemas, de acordo com as diversas posições 
da incógnita, e o significado dos sinais de adição $(+)$ e de equidade $(=)$. Esse tipo de sessão passou a ser feita e no estudo de Haydu et al. (2006), assim como no presente estudo, depois que se constatou que os primeiros participantes não compreendiam que a posição da incógnita podia variar e que isso devia ser levado em consideração na resolução dos problemas. Isso deveria ter sido realizado antes do pré-teste, como no estudo de Henklain e Carmo (2013a, 2013b), ou um novo teste deveria ter sido aplicado para que se averiguasse o efeito desse treino de forma independente ao treino de relações condicionais. Esses procedimentos de controle seriam importantes, pois dificuldades na resolução de problemas relacionadas à posição da incógnita estão relacionadas ao fato de os participantes não terem familiaridade com os sinais de adição $(+)$ e igual $(=)$, conforme sugeriu Hiebert (1982). No presente estudo, assim como no de Hiebert, o desempenho foi afetado pela posição da incógnita, sendo que a maior porcentagem de acertos ocorreu em problemas com a incógnita na posição $c$.

$\mathrm{Na}$ fase de ensino das discriminações condicionais, as participantes aprenderam que um problema específico, por exemplo, em forma de operação, é igual (equivale) ao que é apresentado em forma de sentença-problema. Esse ensino, provavelmente, contribuiu para que as participantes discriminassem que estratégias comuns podem ser usadas para resolver problemas apresentados em diferentes formas. Nesse caso, o estabelecimento de relações de equivalência entre problemas aritméticos em forma de operação, balança e sentença-problema mostrou ser um procedimento relevante para o desenvolvimento de um repertório de comportamentos precorrentes alternativos de resolução de problemas. Isso corrobora a afirmação de Skinner (1969) de que a resolução eficaz de problemas depende não só de habilidades específicas e conhecimentos, mas também da elaboração de regras relacionais eficientes, originadas pelo contato com situações semelhantes no passado.

Assim, os resultados do presente estudo permitem concluir que o ensino de familiarização e a formação de classes de estímulos equivalen- tes, envolvendo diferentes formas de apresentação de problemas aritméticos, contribuíram para melhorar o desempenho de adultos e idosos, em séries de alfabetização, na resolução de problemas com incógnitas em diferentes posições. Além disso, considerando que as quatro participantes estavam a pelo menos 3 anos estudando em classe de alfabetização e apresentavam um porcentagem alta de erros na resolução problemas aritméticos e que desconheciam os símbolos de adição e equidade, é possível afirmar que o procedimento proposto no presente estudo além de ser eficaz, é também é econômico, pois em apenas três sessões as participantes aprenderam a resolver os problemas. Estudos futuros devem ser conduzidos com diferentes populações e com amostras maiores para que se possa comprovar a eficácia do procedimento. Sugere-se ainda que em estudos futuros sejam conduzidas sessões de follow-up.

\section{Referências}

Alain, P., Kauffmann, M., Dubas, F., Berrut, G., \& Le Gall, G. (2007). Fonctionnement exécutif et vieillissement normal: étude de la résolution de problèmes numériques, Psychologie \& NeuroPsychiatrie du vieillissement, 5, 315-225. doi: 10.1684/pnv.2007.0106

Bijou, S. W. (1970). What psychology has to offer education-now. Journal of Applied Behavior Analysis, 3, 65-71. doi:10.1901/jaba.1970.3-65

Carpenter, T. P., \& Moser, J. M. (1983). The acquisition of addition and subtraction concepts. In R. Lesh \& M. Landau (Eds.), Acquisition of mathematic concepts and processes (pp. 7-44). New York: Academic.

Dalto, J. O. (2012). Ensino e aprendizagem de função do primeiro grau por meio do modelo da equivalência de estímulos (Tese de doutorado não-publicada, Universidade Estadual de Londrina, PR, Brasil).

De Rose, J. C., \& Bortoloti, R. (2007). A equivalência de estímulos como modelo do significado. Acta Comportamenlia, 15, 83-102.

Debert, P., Matos, M. A., \& Andery, M. A. P. A. (2006). Discriminação condicional: Definições, procedimentos e dados recentes. Revista Brasileira de Análise do Comportamento, 2, 37-52. 
Del Rey, D. (2009). Análise do comportamento no Brasil: O que foi pesquisado até $2005 \mathrm{em}$ relação aos comportamentos matemáticos (Dissertação de mestrado não-publicada, Pontifícia Universidade Católica de São Paulo, SP, Brasil).

Drachenberg, H. B. (1973). Programação das etapas que levam à modificação gradual no controle de certos aspectos de um estímulo para outro ( $f a d$ ing) na situação de "escolha de acordo com o modelo”. Ciência e Cultura, 25, 44-53.

Fienup, D. M., Covey, D. P., \& Critchfield, T. S. (2010). Teaching brain-behavior relationships economically with stimulus equivalence technology. Journal of Applied Behavior Analysis, 43, 19-33. doi:10.1901/jaba.2010.43-19

Haydu, V. B. (2012). Analise aplicada do comportamento: O que é, como fazer e o que tem sido pesquisado. In V. B. Haydu \& S. R. de Souza (Eds.), Psicologia comportamental aplicada: Avaliação e intervenção nas áreas da saúde, da clínica, da educação e do esporte (Vol. 2, pp. 13-51). Londrina, PR: Editora da Universidade Estadual de Londrina.

Haydu, V. B., Costa, L. P. da, \& Pullin, E. M. M. P. (2006). Resolução de problemas aritméticos: Efeito de classes equivalentes de diferentes formas de apresentação dos problemas. Psicologia: Reflexão e Crítica, 19, 44-52. doi:10.1590/ S0102-79722006000100007

Henklain, M. H. O., \& Carmo, J. S. (2013a). Equivalência de estímulos e aumento de acertos na solução de problemas de adição e subtração. Paidéia (Ribeirão Preto), 23, 349-358. doi:10.1590/1982-43272356201309

Henklain, M. H. O., \& Carmo, J. S. (2013b). Equivalência de estímulos e redução de dificuldades na solução de problemas de adição e subtração. Psicologia: Teoria e Pesquisa, 29, 341-350. doi:10.1590/S0102-37722013000300012

Heward, W. L., Heron, T. E., Neef, N. A., Peterson, S. M., Sainato, D. M., Cartledge, G. Y., ...Dardig, J. C. (2004). Focus on behavior analysis in education: Achievements, challenges, and opportunities. Upper Saddle River, NJ: Prentice Hall.

Hiebert, J. (1982). The position of the unknown set and children's solution of verbal arithmetic problems. Journal for Research in Mathematics Education, 23, 341-349. doi:10.2307/749008
Hübner, M. M. C., \& Marinotti, M. (Eds.). (2004). Análise do Comportamento para a Educação: Contribuições recentes. Santo André, SP: ESETec.

Iégas, A. F. (2003). Software para a resolução de problemas aritméticos: $O$ modelo da balança (Dissertação de mestrado não-publicada, Universidade Estadual de Londrina, PR, Brasil).

Levingston, H. B., Neef, N. A., \& Cihon, T. M. (2009). The effects of teaching precurrent behaviors on children's solution of multiplication and division word problems. Journal of Applied Behavior Analysis, 42, 361-367. doi:10.1901/ jaba.2009.42-361

Lorena, A. B. de, Castro-Caneguim, J. de F., \& Carmo, J. S. (2013). Habilidades numéricas básicas: Algumas contribuições da análise do comportamento. Estudos de Psicologia (Natal), 18, 439446. doi:10.1590/S1413-294X2013000300004

Luna, S. V. (2007). Contribuições de Skinner para a Educação. In V. M. N. de S. Placco. (Ed.), Psicologia \& Educação: Revendo contribuições (2. ed., pp. 1465-179). São Paulo, SP: Editora da Pontifícia Universidade Católica de São Paulo.

Magalhães, P. G. S., Assis, G. J. A., \& Rossit, R. A. S. (2012). Ensino de relações condicionais monetárias por meio de Matching to Sample para crianças surdas com e sem pré-requisitos matemáticos. Revista Brasileira de Terapia Comportamental e Cognitiva, 14, 4-22.

Marmo, A. V. (2002). Publicações sobre Educação no Journal of Applied Behavior Analysis: Uma revisão (Dissertação de mestrado não-publicada, Pontifícia Universidade Católica de São Paulo, SP, Brasil).

Matos, M. A. (1992). Análise de contingências no aprender e no ensinar. In E. S. de Alencar (Ed.), Novas contribuições da psicologia aos processos de ensino e aprendizagem (pp. 141-165). São Paulo, SP: Cortez.

Mayfield, K. H., \& Chase, P. N. (2002). The effects of cumulative practice on mathematics problem solving. Journal of Applied Behavior Analysis, 35, 105-123. doi:10.1901/jaba.2002.35-105

Monteiro, G., \& Medeiros, J. G. (2002). A contagem oral como pré-requisito para a aquisição do conceito de número com crianças pré-escolares. Estudos de Psicologia (Natal), 7, 73-90. doi:10.1590/S1413-294X2002000100009 
Neef, N. A., Nelles, D., Iwata, B. A., \& Page, T. J. (2003). Analysis of precurrent skills in solving mathematics story problems. Journal of Applied Behavior Analysis, 36, 21-33. doi:10.1901/ jaba.2003.36-21

Perez, W., Campos, H. C., \& Debert, P. (2009). Procedimento go/no-go com estímulos compostos e a emergência de duas classes com três estímulos. Acta Comportamentalia, 17, 191-210.

Resende, A. A. C., Elias, N. C., \& Goyos, A. C. N. (2012). Transferência de funções ordinais através de classes de estímulos equivalentes em surdos. Acta Comportamentalia, 20, 317-326.

Rossit, R. A. S., \& Goyos, C. (2009). Deficiência intelectual e aquisição matemática: Currículo como rede de relações condicionais. Psicologia Escolar e Educacional, 13, 213-225.

Sidman, M. (2000). Equivalence relations and the reinforcement contingency. Journal of the Experimental Analysis of Behavior, 74, 127-146. doi:10.1901/jeab.2000.74-127
Skinner, B. F. (1968). The technology of teaching. New York: Appleton-Century-Crofts.

Skinner, B. F. (1969). Contingencies of reinforcement: A theoretical analysis. Englewood Cliffs, NJ: Prentice-Hall.

Skinner, B. F. (1984). An operant analysis of problem solving. The Behavioral and Brain Science, 7, 583-591. doi:10.1017/S0140525X00027412

Zanotto, M. L. B. (2000). Formação de professores: A contribuição da análise do comportamento. São Paulo, SP: Editora da Pontifícia Universidade Católica de São Paulo.

Recebido: 04/12/2012

$1^{a}$ revisão: $10 / 05 / 2014$

Aceite final: 29/07/2014 